\title{
DIÁLOGOS COM PIBIDIANAS/OS DE EDUCAÇÃO FÍSICA/UEM: TRAÇANDO CAMINHOS PARA (RE) PENSAR O CURRÍCULO
}

\author{
BRENDA ZARELLI GATTI \\ ELIANE ROSE MAIO \\ Universidade Estadual de Maringá (UEM), Maringá, Paraná, Brasil
}

\begin{abstract}
Resumo: O presente estudo tem como objetivo geral discutir sobre gênero e sexualidade na formação de professores/as pelo PIBID de Educação Física-UEM. Para isso entrevistamos seis pibidianos/as por meio de entrevista semiestruturada. Os objetivos específicos são: a) verificar se os/as pibidianos/as contaram com alguma formação acadêmica que lhes desse subsídios para a discussão de gênero e sexualidade; b) pesquisar se são discutidas questões de gênero e sexualidade nas aulas aplicadas pelos/as pibidianos/as. Pautamos esse trabalho na perspectiva dos Estudos Culturais. Concluímos que os/as pibidianos/as contaram com uma formação sobre gênero e sexualidade, embora superficial. As aplicações das aulas pelos/as pibidianos/as foram esporádicas, limitando-se ao desejo dos/as bolsistas em querer trabalhar com a temática.
\end{abstract}

Palavras-chave: Educação. PIBID. Gênero. Sexualidade.

INTRODUÇÃO

O presente trabalho é parte da dissertação de mestrado intitulada PIBID de Educação Física/UEM: gênero em debate na formação de professoras/es. (GATTI, 2018). Apresentaremos neste artigo o detalhamento da pesquisa, sendo a primeira parte a descrição da metodologia, apresentação do perfil dos/as entrevistados/as, a inserção no campo de estudos e as categorias de análise. Na segunda parte discorreremos sobre as análises das entrevistas, nas quais utilizamos a análise de conteúdos de Bardin (1979).

Para a coleta de dados, entrevistamos seis pibidianos/as de um total de vinte bolsistas do PIBID de EF/UEM. A coleta foi realizada pela própria pesquisadora e foi permitida e submetida ao COPEP (Comitê Permanente de Ética em Pesquisa com Seres Humanos) sob o número: 32259014.2.0000.0104, e a partir da assinatura do Termo Livre de Consentimento Esclarecido (TCLE).

As entrevistas semiestruturadas foram agendadas com os/as alunos/as que aceitaram participar, e ocorreram entre 9 e 21 de março de 2016, sendo realizadas no "Laboratório de Lúdico" (Sala 02, Bloco M05-UEM), em local reservado e sem possíveis interferências sonoras. Utilizamos um aplicativo de gravação de voz, contido nos smartphones para gravação dos áudios e futura transcrição das entrevistas, com a anuência dos sujeitos entrevistados.

A partir das transcrições das falas dos/as entrevistados/as, buscamos responder aos objetivos específicos deste estudo, que são: a) identificar se foi oferecida disciplina(s) 
sobre gênero na graduação em Educação Física; b) verificar se os/as pibidianos/as discutiram em suas aulas sobre gênero, sexualidade e diversidade sexual como conteúdo sistematizado. Informamos que esses objetivos específicos também serão nossas categorias de análise, já que procuramos alcançá-los e também analisá-los.

O quadro a seguir apresenta os nomes fictícios ${ }^{1}$ dos/as acadêmicos/as e tempo de PIBID.

QUADRO 1: Nomes Fictícios e dados dos/as entrevistados/as

\begin{tabular}{|l|l|l|}
\hline & Nome & Tempo de PIBID \\
\hline $\mathbf{1}$ & Cassia & 4 anos \\
\hline $\mathbf{2}$ & Betânia & 2 anos \\
\hline $\mathbf{3}$ & Renato & 3 anos \\
\hline $\mathbf{4}$ & Vanessa & 2 anos \\
\hline $\mathbf{5}$ & Elis & 3 anos \\
\hline $\mathbf{6}$ & Gal & 3 anos \\
\hline
\end{tabular}

Fonte: a autora.

\section{DISCIPLINAS SOBRE GÊNERO NO CURSO DE GRADUAÇÃO EM EDUCAÇÃO FÍSICA/UEM}

Analisaremos algumas falas dos/as pibidianos/as em relação à questão abordada pela pesquisa, que se refere à existência ou não de alguma disciplina específica que trabalhasse a temática de gênero e sexualidade.

Sem exceção, todos/as afirmaram que não houve nenhuma disciplina específica sobre Gênero e Diversidade Sexual. Contudo, entendemos que existam ainda "muitos obstáculos, tanto nas mentes das professoras, quanto na estrutura da escola, que impedem uma abordagem cuidadosa e ética da sexualidade na educação" (LOURO, 2001, p. 62). Esses obstáculos, para os/as entrevistados/as, podem estar sendo superados, pois de acordo com eles/as, alguns/mas professores/as do Curso discutiam a temática em certo momento nas suas disciplinas. Cassia relatou que:

Não, infelizmente nenhuma. Teve a do 'R', mas assim, não foi inteira, algumas coisas ele tratava em sala e tal..

Questionei-a sobre qual disciplina se tratava, e ela respondeu "Lúdico e Educação". Já Renato afirmou que teve alguns estudos na disciplina de

Teorias do Lazer, com o 'R', e assim, ele trabalha em geral, tem lá o projeto de bairro, então foi mais falado na disciplina dele e em Jogos, brinquedos e brincadeiras, como ele deu no outro ano, mas nada em específico como a gente tem hoje a disciplina de Corpo e Gênero na EF, eu não faço, mas eu não tive nenhuma disciplina assim. $O$ ' $R$ ' 
traz, ele fala assim que tem que ser trabalhado, ele indica referência para pesquisar, mas nada específico (Grifo nosso).

Compreendemos, na fala de Renato, que existem tentativas de um professor em abordar o tema, suscitando a existência de currículos não oficiais trabalhados durante a graduação. Logo, podemos articular essa ideia com a afirmação de Furlani (2011, p. 40) onde, "educadoras e educadores comprometidos com mudanças sociais" buscam mudar as aulas trazendo as temáticas em discussões, mesmo que minuciosas, estes/as "devem procurar perturbar, sacudir as formas de se posicionarem perante as discussões de educação sexual, que tradicionalmente, vem sendo realizadas no Brasil" (ibidem).

Além de uma preocupação sobre mudanças sociais, trazer essas discussões para a graduação recupera, em certa medida, as culturas negadas e/ou marginalizadas historicamente (SANTOMÉ, 2013).

A disciplina de Teorias dos Jogos também foi permeada por discussões sobre sexualidade, conforme relata Betânia, indicando que, apesar de não existir uma disciplina específica, existem pessoas sensíveis aos temas para discutir na academia:

Em Teorias dos Jogos, a gente trabalhou isso, até porque no jogo protagonizado a gente teve que trazer várias questões sociais, então a gente trabalhou bastante sobre isso, a homossexualidade, teve sobre a pedofilia também, focou mais no segundo semestre, mas no decorrer do ano foi mais sobre o preconceito (grifo nosso).

A associação que se faz ao se trabalhar sexualidade em determinados espaços se mostra mais pontual, e ainda é quando parece haver uma aproximação entre a questão homossexual com pedofilia, talvez como possibilidade de justificar uma pela outra ou talvez uma inferência não consciente. Se, de um lado, algumas disciplinas trabalham com esses temas de forma direta ou indireta, outras parecem se valer da noção de demanda, ou seja, esperam que surja alguma postura ou ação para lidar.

Como exemplo, Vanessa relata que a disciplina de Ritmo e Dança não está marcada como específica, mas atravessada por tais demandas, o que corrobora a defesa de Neira e Nunes (2011), ao defenderem que o currículo da EF provoca os sujeitos a se posicionarem no mundo, a demarcar suas identidades e valer-se das mesmas. Vanessa descreve que

Não, são coisas que aparecem no meio da aula e ela pontua assim... ela dá Ritmo e Dança, e assim, na primeira aula, já foi bem impactante relacionando com o contato com o corpo... o corpo dele é diferente do seu? Por quê? Na nossa sala tem uma menina que tem uma opção sexual diferente, e tem uma barreira com ela. Por mais que você esteja no mundo acadêmico e todo mundo considerado adulto, ainda tem uma barreira. $E$ às vezes essas coisas surgem na aula e alguns professores discutem também, a ' $\mathrm{V}$ ' comenta e o próprio 'C'... (grifo nosso).

Observamos na fala de Vanessa que a palavra em ênfase "opção sexual" vem carregada de significado, esse enunciado pode ser entendido como de alguém que desconhece o termo 'orientação sexual'. Entendemos como 'opção' aquilo que se escolhe, 
portanto utiliza-se o termo 'Orientação Sexual', assim como Bortolini (2008b) defende esse termo como sendo explicado por uma atração que pode ser de ordem afetiva e/ou sexual, que uma pessoa sente por uma ou por várias outras pessoas, em um continuum que pode ser manifesto na homossexualidade, heterossexualidade e bissexualidade.

A fala de Vanessa desvelou um senso comum ao se referir à orientação como 'opção' sexual, uma linguagem carregada de subjetividades e que demarca uma confusão constante no âmbito da fala.

O senso comum, baseado em crenças e valores pessoais, fundamenta argumentos como o que confunde opção sexual com orientação sexual, proferidos por grande parcela da população independentemente de outras variáveis sociais como: classe, gênero, intelectualidade, geração. Entretanto, há diferença entre opção e orientação sexual. Quando uma pessoa opta por algo, ela faz uma escolha entre várias ou, no mínimo, entre duas possibilidades. As pessoas com orientação homossexual não optam por se apaixonar e se relacionar intimamente com pessoas do mesmo sexo (SANTOS, ARAÚJO, 2009, p.17).

Para Santos e Araújo (2009), a homossexualidade ou atração afetiva e/ou sexual por pessoas do mesmo sexo não se constitui em doença (sufixo 'ismo'), pois o 'homossexualismo' deixou de ser tratado como doença em 1985, quando o Conselho Federal de Medicina retirou a homossexualidade da Classificação Internacional de Doenças - CID. Em 17 de maio de 1990, durante a 43a Assembleia Mundial da Saúde, a homossexualidade foi excluída da décima revisão da lista de doenças (BORTOLINI, 2008).

Quanto à bissexualidade, Bortolini $(2008$, p.16) define como o/a sujeito/a que "sente atração por pessoas de ambos os gêneros", isso é, um indivíduo que sente desejos sexuais, afetivos e eróticos por pessoas do mesmo gênero ou do gênero oposto. Já, a heterossexualidade é definida como uma pessoa que sinta desejos sexuais, afetivos e eróticos por alguém do gênero oposto.

A respeito da heterossexualidade e da 'opção' sexual, voltaremos a problematizála posteriormente. Ainda na fala de Vanessa, a mesma pontua a disciplina de Ritmo e Dança e dos/as professores/as ' $C$ ' e ' $V$ '. Essas disciplinas destacadas nas falas dos/as sujeitos/as (Ritmo e Dança, Lúdico e Educação, Teorias do Lazer, por exemplo) compõem os currículos das duas habilitações (Licenciatura e Bacharelado) em Educação Física. No caso da disciplina de Ritmo e Dança, era ofertada no currículo de 2007 a 2014 para o primeiro ano do curso, o que é comum para as habilitações de Licenciatura e Bacharelado.

Como diversas disciplinas são apontadas nas falas, faz-se necessário compreender, ainda que de forma rápida, como estão inseridas na grade curricular.

A disciplina de Lúdico e Educação ( $2^{\circ}$ ano do Curso de EF) fazia parte do currículo de Licenciatura e Teorias do Lazer para licenciatura e bacharelado. Com a reestruturação curricular que aconteceu em 2015, a disciplina de Lúdico e Educação tornou se Teorias dos Jogos ( $2^{\circ}$ ano) e Teorias do Lazer em Estudo sobre tempo livre e trabalho ( $3^{\circ}$ ano), comum às duas habilitações. A disciplina de Jogos, brinquedos e brincadeiras faz parte do novo currículo e é ofertada no primeiro ano de graduação. 
Quanto às disciplinas dos/as professores/as ' $\mathrm{V}$ ' e ' $\mathrm{C}$ ', ambos/as lecionam as disciplinas de Fundamentos da Educação Física I e II, respectivamente, no currículo vigente 2007 - 2014. A disciplina de Fundamentos da Educação Física II sofreu mudança no currículo novo, denominada Fundamentos da Educação e da Educação Física, antes ofertada ao segundo ano de licenciatura, agora designada ao terceiro ano da mesma habilitação.

Indiferente à existência de uma disciplina ou diversas que congregam as discussões sobre gênero, as barreiras subjetivas não deixam de existir ou resistir, conforme Vanessa: "Por mais que você esteja no mundo acadêmico e todo mundo considerado adulto, ainda tem uma barreira", o que nos faz repensar o quanto é necessário trabalhar com uma educação sexual emancipatória desde os anos iniciais do Ensino Fundamental, a fim de que a reprodução do discurso heteronormativo se torne algo cristalizado nas crianças, sendo uma fonte de profundas violências e preconceitos (FURLANI, 2011).

Estar no 'mundo acadêmico' não é sinônimo de estar em um ambiente onde o preconceito não exista, ou de estar protegido de violências e de discursos violentos. Os preconceitos não são excluídos e extintos desses lugares de formação humana. Infelizmente, ele está lá, camuflado ou velado, porém não deixa de existir.

A perpetuação e a sofisticação desse sistema de opressão não podem ser compreendidas se não levarmos em conta a existência de instituições que, ao longo da história, estruturam-se em pressupostos fortemente tributários de um conjunto dinâmico de valores, normas e crenças responsável por reduzir à figura do "outro" (considerado estranho, inferior, pecador, doente, pervertido, criminoso ou contagioso) todos/as aqueles/as que não se sintonizassem com os arsenais cujas referências eram, e ainda são, centradas no adulto, masculino, branco, heterossexual, cristão, burguês, física e mentalmente "normal". Tais referências tornaramse, por conseguinte, espaços em que rotineiramente produzem e reproduzem preconceitos que movimentam discriminações de classe, cor, raça/etnia, sexo, gênero, orientação sexual, capacidade físico-mental, crença etc (PRADO, JUNQUEIRA, 2011, p. 52).

Por conseguinte, Louro (2014) afirma que a instituição escolar reproduz diferenças, distinções, desigualdades, que desde seu início separou sujeitos/as e dividiuos por crença, classes e também separou meninos e meninas por meio de múltiplos mecanismos de classificação, ordenamento e hierarquização. Compreendemos que o "mundo acadêmico" (aqui entendemos como a universidade) ou escolar produzem e reproduzem esses preconceitos, logo não sendo um ambiente emancipado dessas violências.

Entretanto, Silva (2015) considera o currículo como espaço de disputa, e essa ideia nos possibilita problematizar discriminações, preconceitos e violência como uma forma de resistência ao currículo heterossexual, branco, cristão e burguês.

Questionamos Vanessa sobre a possível homossexualidade de sua colega de classe. Ela respondeu que 
Diálogos com pibidianas/os de Educação Física...

ela é assumida, mas ela não fala sobre isso. E ela já foi bem excluída assim, não pela opção, mas porque ela é mais velha, a educação dela foi diferente, então ela fazia umas perguntas assim e a galera zoava ela, começava a rir, tipo... 'pergunta idiota' então ela foi se fechando assim... se excluindo.

Entrevistadora: Mas o preconceito é por conta dela ser mais velha ou ela ser lésbica?

Depende... assim, uma vez, ela curtiu a foto da menina no Facebook... aí essa menina excluiu ela do Facebook porque achou que ela tava gostando da menina. E a galera ficou zoando ela, tipo 'ah! ela está te querendo' zoando ela e tal.... e ela se fechava. Uma vez, eu fui conversar com ela e ela falou que 'o povo da sala acha que porque sou lésbica eu vou sair agarrando todo mundo, e não é assim. As meninas têm essa barreira achando que eu vou sair agarrando e eu não vou' (Vanessa).

A fala de Vanessa possui contradições: em um momento afirma que a acadêmica sofre preconceito por ser mais velha e fazer perguntas 'idiotas' e, em outro momento, ao ser questionada pela causa da exclusão da acadêmica, responde que 'depende', ou seja, sugere-se que não seja somente pelo fator idade e por fazer questionamentos 'bobos', mas também está relacionado à orientação sexual 'diferente' da heterossexual.

Louro (2000, p. 45) argumenta que há uma dimensão política em tudo isso, ao apresentar que

[...] formas novas de união e relacionamento entre os gêneros ou o reconhecimento público da homossexualidade não podem ser sumariamente remetidos ao âmbito privado, à simples questão de "opção" pessoal que não interessa a ninguém, além dos indivíduos direta ou imediatamente envolvidos. Essa visão individualista, às vezes, até pode estar conectada a uma posição de tolerância em relação àqueles que vivem uma forma não hegemônica da sexualidade ou de relacionamento, desde que esses se mantenham discretos, escondidos, "na deles". [...] A heterossexualidade afirma-se em contraposição à homossexualidade e à bissexualidade. A visibilidade e o reconhecimento social de novas formas de sexualidade ou de novas formas de relação entre os gêneros têm certamente efeitos sobre as formas tradicionais. Não há como fugir disso.

Há de se pensar que as pessoas ainda constroem 'barreiras' ao lidar com o/a 'outro/a'. Como aponta Louro (2007, p.19), as sociedades realizam esses processos e, então "[...] constroem os contornos demarcadores das fronteiras entre aqueles que representam a norma (que estão em consonância com seus padrões culturais) e aqueles que ficam fora dela, às suas margens". Ou seja, a 'opção' é o que está fora dessa norma, "[...] gays e lésbicas são descritos como desviantes da norma heterossexual" (LOURO, 2007, p.19). 
Butler (2003) utiliza o termo 'heterossexualidade compulsória' para a sequência normativa sexo-gênero-sexualidade. A autora descreve que esse termo foi historicamente e culturalmente concebido como norma, sendo a heteronormatividade resultante dessa.

Ao se usar a expressão 'opção sexual', há a necessidade de problematizar a heteronormatividade. Compreendemos que essa expressão

[...] foi construída historicamente e se refere à conceituação e propagação da heterossexualidade como "normal" e/ou "regra" nas sociedades, em detrimento da homossexualidade. Na sociedade contemporânea, o gênero está ligado à heterossexualidade, pois logo que a criança nasce é educada/disciplinada para adquirir o gênero "correto". A partir daí, para estar dentro dos padrões, ela obrigatoriamente tem que se sentir atraída por uma pessoa do sexo oposto (SANTOS; ARAUJO, 2009, p.20).

Portanto, essa construção e propagação à 'norma' heterossexual, pois a orientação sexual do/a 'outro/a' é tida como 'diferente' dessa norma, como se referiu Vanessa à 'opção' de sua colega de curso, por estar fora da normatividade e da normalidade.

Lionço e Diniz (2009) afirmam que a heterossexualidade é ensinada desde cedo como 'natural', e afirmam que a escola é um espaço de expressão das sexualidades de todos os/as sujeitos/as, e, dessa maneira, também é o ambiente em que se manifestam preconceitos e discriminações contra aqueles/as que não se enquadram nos padrões e nas normas sociais de identidade e de orientação sexual. Logo, há a necessidade de que escola e universidade busquem construir um currículo que discuta gênero e sexualidade, respeitando a diversidade sexual

\begin{abstract}
A heterossexualidade é concebida como "natural" e também como universal e normal. Aparentemente supõe-se que todos os sujeitos tenham uma inclinação inata para eleger como objeto de seu desejo, como parceiro de seus afetos e de seus jogos sexuais alguém do sexo oposto. Consequentemente, as outras formas de sexualidade são constituídas como antinaturais, peculiares e anormais. É curioso observar, no entanto, o quanto essa inclinação, tida como inata e natural, é alvo da mais meticulosa, continuada e intensa vigilância, bem como do mais diligente investimento (LOURO, 2007, p. 13).
\end{abstract}

A partir disso, podemos notar necessidade de uma Educação que desconstrua o modelo heteronormativo presente nos ambientes educacionais, de forma que o/a aluno/a entenda a diversidade sexual da vida humana.

Concordamos com Furlani (2009, p.39) ao apresentar que

[...] para muitos/as educadores/as, a opção em não discutir as sexualidades e os gêneros pode ser apoiada pela "providencial" inexistência da temática nos currículos escolares (que justificaria sua recusa na discussão e o conveniente apego aos Conteúdos Curriculares propostos). Ou ainda poderia estar favorecida pela ausência da temática nos seus Cursos de formação (que somaria a dificuldade pessoal com o assunto). 
Estar presente nos currículos uma disciplina que discuta a temática não é sinônimo de uma discussão emancipada sobre o assunto, já que esse permite trabalhar de outras formas com uma visão conservadora e religiosa. Contudo, como nos referimos anteriormente, o nosso objetivo é discutir o assunto de forma a problematizar, discutir e desconstruir preconceitos de gênero, bem como de sexualidade e identidades.

No decorrer das entrevistas alguns pontos nos despertaram interesse, um deles foi que as pessoas entrevistadas narraram sobre a importância da EF em discutir gênero, sexualidade e diversidade sexual nas aulas, talvez por pensarem em uma estrutura demarcada com base no próprio corpo e corporeidades.

Sim... eu penso que sim, se não tivesse isso básico na escola como é o meu caso, eu não teria em lugar nenhum. Então às vezes como é passado isso fora de casa, na rua tem que ter um certo cuidado. Eu acho que deveria ter, mas não só na $\mathrm{EF}$, tinha que ter nas outras disciplinas também que têm esse cunho biológico. Algo mais interdisciplinar, mas é lógico que deveria ser trabalhado (Elis).

Sim, até mesmo porque a gente vê várias formas de amar, porque quem tem maldade é o adulto, a criança não vê maldade... então acho que teria que ser trabalhado, sim. Conforme a convivência da criança com alguém preconceituosa ela aprende também (Betânia).

Não houve discordância de nenhum/a entrevistado/a quanto à discussão do assunto pela EF.

Sim, com certeza. A gente vê poucos professores trabalhando de maneira isolada. A gente vê por aí muito preconceito por parte de professor e aluno, isso tem que acabar, né?! Ninguém gosta de sofrer preconceito e pior se ele vier de um professor que tá formando essas crianças... se esses alunos vêm de uma educação familiar preconceituosa esse aluno vai chegar na escola e reproduzir o que os pais falam em casa e, muitas vezes, os professores ajudam fazendo piadas ou não ligam quando um aluno faz piada homofóbica com o amiguinho (Cassia).

Para a acadêmica Elis esse "cunho biológico" da EF permite falar sobre o tema. Entretanto, discordamos dessa afirmação, pois compreendemos que foi a influência da área de Ciências Humanas (sobretudo, Sociologia e Filosofia) que nos deu a possibilidade de questionar essas normas de gênero, de comportamento e de sociedade.

Conforme as narrativas pontuadas, inexiste uma disciplina específica que trabalhe questões de gênero na EF. Contudo, existem aquelas que trabalham, mesmo que de forma transdisciplinar, orientadas segundo as disposições subjetivas de quem as ministram. O currículo, entendido como dinâmico e território de disputas, não pode ser considerado como algo fechado e imutável, uma vez que depende das demandas e do reconhecimento de grupos antagônicos (SILVA, 2015), o que legitima pensar uma graduação como permeada pelas discussões feministas e de gênero que se iniciaram após os anos de 1980. 
Uma vez que tratamos das relações de aproximações entre gênero e sexualidade dispostos em disciplinas, parece pertinente discutir como pibidianos/as aplicaram suas aulas do subprojeto de EF/UEM, como veremos na próxima subseção.

\title{
AULAS APLICADAS PELOS/AS PIBIDIANOS/AS SOBRE GÊNERO, SEXUALIDADE E DIVERSIDADE SEXUAL
}

A existência de disciplinas que acabam por trazer discussões de gênero pode auxiliar pibidianos/as nas aulas práticas, pontuando referenciais não só corporais, mas também culturais, nos espaços escolares.

No PIBID de EF/UEM, as aulas são ministradas por uma dupla de pibidianos/as e acontecem com a supervisão de um/a professor/a da área, lotado/a na escola parceira. No PIBID de Educação Física da UEM, cada dupla é responsável por uma turma (Ensino Fundamental ou Médio) e nela aplicam uma aula por semana conforme acordo com o/a professor/a supervisor/a. Portanto, o/a mesmo/a tem uma das duas aulas semanais para lecionar o seu conteúdo planejado, a outra hora/aula destina-se à dupla de pibidianos/as, utilizando-a para ministrar as aulas do subprojeto (GATTI, 2013).

Questionamos os/as pibidianos/as se trabalharam gênero, sexualidade e diversidade sexual em suas aulas. Apenas a Betânia confirmou nunca ter aplicado nenhuma aula sobre o assunto. Já Cassia narra que em 2015 ela acabou por trabalhar a temática, porque em sua turma havia uma aluna lésbica e na outra sala estudava a sua namorada. As duas sofriam preconceito pela família e, então, resolveram fugir de casa, ficando duas semanas sem aparecer na escola e em suas casas.

\begin{abstract}
[...] ninguém sabia delas e na escola... na sala eu nunca ouvi algum tipo de preconceito, muito pelo contrário elas sempre foram bem vistas, assim... conversavam com todo mundo e eram amigas de todo mundo. E assim, até os meninos, os professores a diretora, todo mundo sabia e nunca tratavam com indiferença com algum tipo de preconceito. Mas, como elas estavam sofrendo esse tipo de preconceito em casa, aí elas resolveram tomar essa atitude. Até que os pais ligaram na escola. A escola também resolveu procurá-las, até que o dia que elas voltaram e a gente resolveu fazer uma aula para fazer uma discussão sobre isso, de como eles viam essa situação... para ajudar elas. Para elas entenderem, que pelo menos naquele ambiente ali, aquelas pessoas as acolhiam (Cassia).
\end{abstract}

A mesma acadêmica também nos relatou que, com a mudança do Conteúdo Estruturante e do orientador do PIBID de EF/UEM, no final de 2013 e início de 2014, tornou-se mais difícil tratar esses assuntos.

Com o 'R' foi mais, como nós trabalhávamos com os jogos, brinquedos e brincadeiras a gente tinha mais liberdade para tratar essas questões, não que nós não tratássemos com o Professor ' $C$ ', mas quando ele entrou no projeto mudou o conteúdo, nos trabalhamos agora com Esporte [Badminton]. Então tem ficado mais difícil de tratar, mas mesmo assim é... não diretamente, mas algumas 
questões nós víamos de reação dos alunos na sala então fez com que a gente trabalhasse (Cassia, grifo nosso).

Cassia descreve a dificuldade de em tratar sobre esses assuntos com a mudança do Conteúdo Estruturante, mas que em alguns momentos trabalhando com o Esporte (Badminton) essas temáticas eram abordadas, pois 'surgiam' no decorrer das aulas. A Capes (2012) deixa demarcada em relação ao PIBID, que o modelo de estágio deve priorizar as múltiplas vivências de aspectos pedagógicos escolares, o que se constitui como essencial para bolsistas.

Assim como Cassia, Gal relatou que o Professor ' $C$ ' havia deixado livre à escolha do Conteúdo Atravessador ${ }^{2}$ a ser tratado em aula, bem como os jogos e brinquedos que queriam levar para discuti-los, mas assuntos sobre gênero e sexualidade

[...] são assuntos que não têm como não ser tratado, porque dentro do trabalho surgem questões "ah! homem ganha mais que mulher" então sempre envolvem essas questões e não têm como não ser trabalhados (Gal).

Fica subentendido que, para Gal, a discussão sobre gênero está explícita nas aulas, e, mesmo que este não esteja no planejamento, acontecem momentos durante as aulas que possibilitam tratar do tema. Mas, como dissemos anteriormente, gênero e sexualidade não "surgem" durante as aulas porque fazem parte da vida humana, portanto não é algo que posso ser desligado ou algo do qual alguém possa se despir, ou apenas deixado fora da sala de aula (LOURO, 2014). Referente a isso, Elis evidencia que, em suas aulas, não deixa que esses assuntos passem despercebidos.

Quando eram nossas aulas, a gente nunca deixava passar despercebido. A gente primeiro procurava questionar os alunos, do porquê ele estava fazendo aquilo, porque aquele esporte é para menino, fazendo ele provar aquilo que estava falando. Então era assim que a gente acabava derrubando os preconceitos e deixava claro para os alunos que ali não existia preconceito, diferença dentro da sala, e toda vez que acontecia a gente ia lá e bem na hora que acontecia, a gente ia bem direto na ferida mesmo.

Para Elis, os brinquedos produzidos pelos/as acadêmicos/as do Curso de EF foram fundamentais para abordar esses assuntos em sala de aula. Deixa transparecer o cruzamento entre a teoria e prática, aliado aos objetivos que o PIBID demarca: promover múltiplas vivências nos espaços escolares (CAPES, 2009; 2012). Para que isso se efetive, o planejamento se faz necessário tendo como norteador o Conteúdo Atravessador.

Até quando a gente prepara aula, a gente pensava no Conteúdo Atravessador, no tema, alguma coisa assim... eu trabalhei, mas trabalhei pouco... eu trabalhei mais quando PIBID iniciou no ano retrasado [2013] com os Jogos, brinquedos e brincadeiras, então a gente pegou muito dos jogos e dos brinquedos que foram produzi- 
dos pelos acadêmicos na época do ' $\mathrm{R}$ ' e tinham vários desses brinquedos que abordavam esses temas e a gente levou isso para sala de aula... então, quando eu trabalhei foi mais nesses momentos, com os brinquedos e com os jogos promovidos (Elis).

A produção de materiais, como brinquedos, faz parte do projeto do PIBID de EF/UEM com intuito de relacionar o cotidiano a temas como questões étnico raciais, cidadania, trabalho e infância, linguagem, comunicação e outras correlações, objetivando, ainda, uma "intervenção pedagógica com brinquedos artesanais críticos" (OLIVEIRA, 2013, p. 1).

$\mathrm{Se}$, de um lado, algumas pessoas têm contato apenas no PIBID de EF com questões de gênero, de outro, pessoas como Gal trazem uma narrativa demarcada pela inserção em movimentos acadêmicos que serviram de base para discussões sobre mulher e gênero. Em sua fala, Gal informa a importância de estar envolvida desde o seu primeiro ano de graduação com o Movimento "Mulheres em Luta" ${ }^{3}$, que essa vivência foi essencial para seu aprendizado e pôde, assim, levar essas discussões para a sala de aula.

No meu primeiro ano de graduação, eu fazia parte do Movimento Mulheres em Luta, então as reuniões, os estudos que a gente tinha lá, eu já tinha assim comigo no pessoal, não tinha estudo, não tinha nada, e as coisas que eu fui aprendendo de fora, eu digo do outro grupo, eu fui levando para dentro da sala de aula. Até mesmo no Marxlutte a gente estudou o texto do Engels 'A Origem da Família, da propriedade privada e do Estado', eu acho que antes não era patriarcal, eram as mulheres que comandavam, eram sociedades matriarcais. Então, assim, no meu primeiro ano foi bem enriquecido e com bastante conteúdo para levar para sala (Gal).

Conseguimos verificar nos relatos que os/as acadêmicos/as obtiveram maior relação com o Conteúdo Estruturante Jogos, Brinquedos e Brincadeiras, por consequência dos brinquedos artesanais produzidos serem temáticos, abordando vários temas como relações de gênero, sexualidade, violência de gênero, preconceitos contra LGBT, negros/as, classe, religião, padrão corporal etc. Todos esses fatores contribuíram para que os/as pibidianos/as os trabalhassem em sala de aula, o que não aconteceu sistematicamente com o conteúdo Esporte.

O acadêmico Renato descreve seu trabalho com o Conteúdo Estruturante Jogos, Brinquedos e Brincadeiras a partir do Conteúdo Articulador: Violência de gênero, em uma turma de $9^{\circ}$ ano de um colégio estadual, relatando que

assim... quando eu e o 'A' tentamos trabalhar a violência contra a mulher, a gente pegou desde lá no começo, com o livro a Origem da Família, da propriedade privada e do Estado, e pegamos da instituição da família lá no começo que como era, eram tribos, eram gens e que iam avançando, e que as mulheres que cuidavam da casa, elas que mandavam, que todas as mães eram mães de todos os filhos, essas relações foram avançando e que os alunos ficavam bem assustados assim, com relação ao incesto e que a mulher poderia mandar o homem para fora de casa, e que para eles a questão é que o homem manda na casa e que o que houve com a mulher antes era 
algo fora da realidade. Então, para a gente trazer isso para eles, era bem diferente assim... que não era algo no cotidiano deles (Renato). Questionamo
temática, e descreve

eu não lembro direito do porquê, mas não foi nenhum caso assim de que aconteceu algo na escola que a gente precise falar, a gente escolheu mais assim, por afinidade e por nunca ter visto alguém trabalhando, também. Porque no geral você não vê ninguém trabalhando esses assuntos (Renato).

Renato, ao descrever sua afinidade com o tema, relata também nunca ter visto professores/as trabalharem o assunto, o que nos faz questionar quantas violências deixariam de ser realizadas, assim como seriam evitados feminicídios e estupros contra as mulheres e crianças caso esses conteúdos fossem discutidos nas aulas dos cursos de licenciatura no Ensino Superior e na Educação Básica, como disciplina obrigatória.

O bolsista Renato disse que seu colega, também pibidiano, que denominamos como 'A' foi à Delegacia da Mulher de Maringá buscar alguns dados para expor em suas aulas. Descreveu também a relação dos/as alunos/as da sua turma, principalmente a inquietação das meninas ao saber da opressão histórica a que as mulheres foram submetidas durante séculos, e o quão alarmantes são os casos de violência contra a mulher registrados em Maringá. O trabalho dos/as pibidianos/as sobre a violência da mulher foi de 1 bimestre, como constava no planejamento da dupla.

As meninas falavam mais, elas ficavam inquietas, se perguntavam 'por que eu tenho que cozinhar? Por que eu tenho que arrumar a casa na hora que eu chego da escola? Por que eu tenho que cuidar do meu irmão? Por que eu não posso sair?... não posso isso, não posso aquilo...' E os meninos ficam mais espantados, assustados, mas geralmente não falam nada (Renato).

[...] o 'A' foi na Delegacia da mulher e ele comprou até um livro sobre o assunto. Ele fez um levantamento sobre a violência contra a mulher. A gente levou os dados para eles e algumas imagens, e algumas não dava para mostrar porque eram imagens fortes e não dava para mostrar isso para eles. A gente mostrou quantas mulheres foram agredidas em Maringá, isso e aquilo, eu não me recordo certo do número, mas eram números espantosos assim... e fora o que não é dito, né?... (Renato).

Salientamos aqui alguns pontos da Lei Maria da Penha (BRASIL, 2006), Lei 11340/06 Lei no 11.340, de 7 de agosto de 2006, que são essenciais para esse estudo e para um projeto de Educação sem violências, aqui, especificamente a de gênero.

A Lei Maria da Penha em seu Título III "Da assistência à mulher em situação de violência doméstica e familiar", capítulo I "Das medidas Integradas de Prevenção", artigo 80, nos incisos I, V, VIII e IX elucidam que 
I - a integração operacional do Poder Judiciário, do Ministério Público e da Defensoria Pública com as áreas de segurança pública, assistência social, saúde, educação, trabalho e habitação;

V - a promoção e a realização de campanhas educativas de prevenção da violência doméstica e familiar contra a mulher, voltadas ao público escolar e à sociedade em geral, e a difusão desta Lei e dos instrumentos de proteção aos direitos humanos das mulheres;

VIII - a promoção de programas educacionais que disseminem valores éticos de irrestrito respeito à dignidade da pessoa humana com a perspectiva de gênero e de raça ou etnia;

IX - o destaque, nos currículos escolares de todos os níveis de ensino, para os conteúdos relativos aos direitos humanos, à equidade de gênero e de raça ou etnia e ao problema da violência doméstica e familiar contra a mulher (BRASIL, 2006, p.1).

Essa Lei (BRASIL, 2006) não obriga o trabalho, mas permite e incentiva a realização de campanhas educativas de prevenção à violência contra a mulher, destinadas à Educação, e acima de tudo, destaca que nos currículos escolares de todos os níveis de ensino possuam conteúdos relativos à violência doméstica, equidade de gênero, raça/etnia e aos direitos humanos.

Para isso, defendemos que de fato se tenha( $m)$ nos currículos oficiais escolares e de formação de professores/as em nível superior, disciplina(s) referente(s) ao que foi disposto nessa Lei Maria da Penha, mesmo que os Planos Nacionais, Estaduais e Municipais (dentre eles o PME de Maringá) de Educação tenham retirado as palavras "gênero" e "identidade de gênero" do seu conteúdo por pressão religiosa. Portanto, a referida lei nos dá base legal para discutir igualdade de gênero, raça e etnia, violência doméstica e direitos humanos nas escolas e universidades.

\section{CONSIDERAÇÕES FINAIS}

Podemos constatar que houve um trabalho sobre gênero e sexualidade pelo PIBID de EF/UEM, porém não de forma global e sistematizada, concomitantemente não apresentadas no projeto institucional do PIBID de EF/UEM. Quanto às aplicações das aulas pelos/as pibidianos/as, identificamos que foram esporádicas, limitando-se ao desejo dos/as bolsistas em trabalhar com a temática, e, portanto, não era obrigatória a discussão do conteúdo.

A partir das falas dos/as entrevistado/as percebemos que os coordenadores do subprojeto de EF/UEM pouco discutiram nas reuniões questões pertinentes às temáticas, mesmo os conteúdos atravessadores elaborados no e pelos/as participantes dos subprojetos junto ao coordenador da época (professor 'R'). Não houve um estudo aprofundado dos conteúdos atravessadores após a sua elaboração, conforme alguns/mas pibidianos/as disseram, e eles/as mesmos/as buscaram por esses conhecimentos fora das reuniões do subprojeto.

Mesmo não constando no projeto institucional, essas questões podem ser trabalhadas. A escola não está isenta de preconceitos, violências e discriminações, portanto sugerimos a inclusão dessas temáticas, tanto no projeto institucional quanto nas graduações em licenciatura, especificamente para esse estudo na Educação Física. 


\section{DIALOGUES WITH STUDENTS OF PHYSICAL EDUCATION/USM: ESTABLISHING WAYS TO (RE)THINK THE CURRICULUM}

ABSTRACT: The present study has as general objective to discuss on gender and sexuality in the formation of teachers by PIBID of Physical Education - USM. For this we interviewed six pibidianos / as by means of semi-structured interview. The specific objectives are: a) to verify if the pibidianos / had some academic formation that gave them subsidies for the discussion of gender and sexuality; B) research on the classes applied by the pibidianos / as if issues of gender and sexuality are discussed. We put this work in perspective of Cultural Studies. We conclude that the pibidianos / as had a formation on gender and sexuality, but superficial. The applications of classes by the pibidianos / as were sporadic, limiting themselves to the affinity of the scholarship holders in wanting to work with the theme.

KEYWORDS: Education. PIBID. Genre. Sexuality.

\section{LOS DIÁLOGOS CON PIBIDIANAS/OS DE EDUCACIÓN FÍSICA/UEM: ESTABLECIENDO CAMINOS PARA (RE) PIENSAR EL CURRÍCULO}

RESUMEN: Lo presente estudio tiene como objectivo general discutir acerca género y sexualidad en la formación de profesores/as por el PIBID de Educación Física - UEM. Por lo tanto hemos interrogado seis pibidianos/as por medio de la entrevista semiestructurada. Los objectivos específicos son: a) verificar se los/as pibidianos/as tuvieron alguna formación académica que les den subvenciones para la discusión de género y sexualidad; b) encuestar cuanto a las clases aplicadas por los/as pibidianos/as son discutidas questiones de género y sexualidad. Basamonos lo trabajo en la perspectiva de los Estudios Culturales. Concluimos que los/as pibidianos/as han tenido formación acerca del asunto, sin embargo, fue poco profundo. Las clases de los/as pibidianos/as fueron ocasionales, limitandose a afinidad de los/as académicos/as in desear trabajar con el asunto.

PALABRAS CLAVE: Educación. PIBID. Género. Sexualidad.

\section{NOTAS}

1) Decidimos utilizar nomes fictícios de cantoras/es brasileiros para preservar a identidade das/os pibidianas/os.

2) Os Conteúdos Atravessadores foram elaborados pelo PIBID de Educação Física (UEM) a partir das Diretrizes Curriculares de Educação Física do Estado do Paraná (2008), e encontram-se descritos no estudo de (GATT, 2013).

3) O Movimento Mulheres em Luta foi um grupo de estudos formado por mulheres universitárias da UEM e da comunidade externa, criado em 2012.

\section{REFERÊNCIAS}

BARDIN, L. Análise de Conteúdo. Lisboa: Edição 70, 1979. 
BONI, V.; QUARESMA, S. J. Aprendendo a entrevistar: como fazer entrevistas em Ciências Sociais. Revista Eletrônica dos Pós-Graduandos em Sociologia Política da UFSC, Florianópolis, v. 2, n. 01, jan-jul. 2005, p. 68-80.

BORTOLINI, A. Diversidade sexual e de gênero na escola uma perspectiva inter-relacional e intercultural. In: BORTOLINI, A. (Org.). Diversidade sexual e de gênero na escola: Educação, Cultura, Violência e Ética. 1a Ed. Rio de Janeiro: Pró-reitora de Extensão/UFRJ, 2008b, p. 26-51.

BRASIL. Lei Maria Maria da Penha. Lei n 11.340, de 7 de agosto de 2006. Coíbe a violência doméstica e familiar contra a mulher. Secretaria Especial de Políticas para as Mulheres. Presidência da República, Brasília, 2007. Disponível em: <http://www.planalto.gov.br/ccivil_03/_ato2004-2006/2006/lei//11340.htm>. Acesso em: 20 jan 2017.

BUTLER, J. Problemas de Gênero. Rio de Janeiro: Civilização Brasileira, 2003.

FURLANI, J. Educação sexual na sala de aula: relações de gênero, orientação sexual e igualdade étnico-racial numa proposta de respeito às diferenças. $1^{\mathrm{a}}$ Ed. Belo Horizonte: Autêntica, 2011.

FURLANI, J. Encarar o desafio da educação sexual na escola. In: PARANÁ. Secretaria de Estado da Educação. Superintendência de Educação. Departamento de Diversidade. Núcleo de Gênero e Diversidade. Sexualidade. Curitiba: SEED. 2009, p. 37-48.

GATTI, Brenda Zarelli. Pedagogia Histórico-Crítica e Educação Física no âmbito do PIBID da UEM/PR. Monografia - Departamento de Educação Física, Universidade Estadual de Maringá, Maringá, 2013. Disponível em: <www.def.uem.br/geraMonografia.php?id=577>. Acesso em: 29 jul. 2020.

LIONÇO, T.; DINIZ, D. Homofobia, silêncio e naturalização: por uma narrativa da diversidade sexual. In: LIONÇO, T.; DINIZ, D. (Org.). Homofobia \& Educação: um desafio ao silêncio. Brasília: Letras Livres/EdUnB, 2009. p. 47-72.

LOURO, G. L. Gênero, sexualidade e educação: uma perspectiva pós-estruturalista. 16a Ed. Petrópolis/RJ: Vozes, 2014.

LOURO, G. L. Pedagogias da sexualidade. In: LOURO, G. L. (Org.). O corpo educado: pedagogias da sexualidade. Tradução de Tomaz Tadeu da Silva. $2^{a}$ ed. $3^{a}$ reimpressão. Belo Horizonte: Autêntica, 2007, p. 7-34.

LOURO, G. L. Currículo, gênero e sexualidade. Porto/Portugal: Porto Editora, 2000.

NEIRA, M. G.; NUNES, M. L. F. Contribuições dos Estudos Culturais para o currículo da Educação Física. Revista Brasileira de Ciências do Esporte. Florianópolis, v.33, n.3, p.671- 
Diálogos com pibidianas/os de Educação Física...

685, jul/set. 2011. Acesso em: <http://www.scielo.br/pdf/rbce/v33n3/a10v33n3>. Acesso em 17 jan 2017.

OLIVEIRA, R. M. PIBID Educação Física - UEM: Pedagogia Crítica, Formação e suas relações com o conteúdo Jogos, Brinquedos e Brincadeiras. In: II ENCONTRO DO PIBID/UEM Anais... Licenciaturas: Impactos e resultados. Maringá: UEM, 2013. p. 17-18.

PRADO, M. A. M.; JUNQUEIRA, R. Diniz. Homofobia, hierarquização e humilhação social. In: VENTURI, G.; BOKANY, V. (Orgs.). Diversidade sexual e homofobia no Brasil. $1^{\text {a }}$ Ed. São Paulo: Editora Fundação Perseu Abramo, 2011, p.51-71.

SANTOMÉ, J.T. As culturas negadas e silenciadas no currículo. In: SILVA, T. T. (Org.). Alienígenas na sala de aula: uma introdução os estudos culturais em Educação. $11^{\mathrm{a}} \mathrm{Ed}$. Petrópolis/RJ: Vozes, 2013, p.155-172.

SANTOS, D. B. C.; ARAUJO, D. C. PARANÁ, Secretaria de Estado da Educação. Superintendência da Educação. Departamento da Diversidade. Núcleo de Gênero e Diversidade Sexual. Caderno Temático de Sexualidade. Curitiba, PR. Imprensa Oficial do Estado do Paraná, 2009, 216 p. (Coleção Cadernos Temáticos da Diversidade).

SILVA, T. T. Documentos da Identidade: uma introdução às teorias do currículo. $3^{a}$ ed. Belo Horizonte: Autêntica, 2015.

\footnotetext{
Brenda Zarelli Gatti: Mestre em Educação pelo Programa de Pós-Graduação em Educação na Universidade Estadual de Maringá (PPE/UEM) e graduada em Educação Física.

Orcid: https://orcid.org/0000-0001-9389-3706

E-mail: brenda_zarelli@hotmail.com

Eliane Rose Maio: Professora do Programa de Pós-Graduação em Educação na Universidade Estadual de Maringá (PPE/UEM), Doutora em Educação Escolar (UNESP) e coordenadora do Núcleo de Estudos e Pesquisas em Diversidade Sexual (NUDISEX). Orcid: https://orcid.org/0000-0002-9280-9864

E-mail: elianerosemaio@yahoo.com.br
} 